\title{
CARNIVOROUS PLANT CULTIVAR NAMES AND PATENTS
}

JAN SCHLAUER •D-60594 Frankfurt/Main•Germany•jan@carnivorousplants.org

Over the years, several carnivorous plants have been patented in a number of countries. This has resulted in some confusion about patents and registered names of carnivorous plants. Here is a short clarification.

Cultivar plants are not registered whatsoever. Established names of cultivars may be registered. This is effected only and exclusively by inclusion of the name in the International Register that is governed by the appropriate International Cultivar Registration Authority (ICRA) accredited with the International Society for Horticultural Science (ISHS).

In the case of carnivorous plants, the appropriate ICRA is the ICPS, nothing else. The publication of a new cultivar name can only be effected by (hard copy) print. Electronic publication, especially if ephemeral, is definitely not suitable.

Please note that a cultivar name, in order to be established, must be free for everyone to use worldwide. It must thus be different from any trademarks (which may exist for the same plant). Usually patents are granted for certain varieties (not cultivars) that should be sold under a certain proprietary brand name (trademark). Such names are not cultivar names and cannot be registered (they cannot be established because they are not free for everyone to use worldwide).

Patents and trademarks are national competence, so they are valid and can be enforced only in the country that granted them. Both are tools to protect the originator's market exclusivity (within certain limits).

Cultivar name registration is of immediate, global relevance to everyone who cares (no enforcement beyond common understanding) for horticulture and the International Code of Nomenclature for Cultivated Plants (ICNCP). It serves to facilitate identification of and to provide some basic information on cultivars and the criteria to distinguish them.

\section{LITERATURE REVIEW}

JAN SCHLAUER •D-60594 Frankfurt/Main•Germany • jan@carnivorousplants.org

Mathieson, M.T., and Thompson, S.L. 2020. Drosera buubugujin M.T.Mathieson (Droseraceae, Drosera section Prolifera C.T.White), a spectacular new species of sundew from the Cape York Peninsula bioregion. Austrobaileya 10(4): 549-557.

This novelty pushes the (known) northern limit of $D$. sect. Prolifera by more than $100 \mathrm{~km}$. While they are geographically nearest to $D$. prolifera, the plants resemble $D$. schizandra so much that they could be conspecific. Unfortunately, the plants are so difficult to access that no genetic or chemical investigation that could test this hypothesis appears feasible in the near future. 